\title{
Problems of axiomatizing religion
}

\author{
Paul Weingartner ${ }^{1}$ (D)
}

Accepted: 17 June 2021 / Published online: 31 August 2021

(C) The Author(s) 2021

\begin{abstract}
The paper discusses problems which arise in attempts to axiomatize parts of religion or religious belief systems. Besides those problems already investigated by Bochenski, like that of the propositional content or the meaning of religious discourse there are several further ones. This paper deals with the question whether full Classical Logic is suitable, whether one universe of discourse is sufficient, how to use definitions and analogous concepts and whether justifications satisfy credibility criteria.
\end{abstract}

Keywords Axiomatizing religion · Logical Structure of Religion · Credibility of religion · Logical Structure of Religious Discourse

In this paper, I shall discuss some problems coming up if one applies logic to religion in such a way as to axiomatize a part of religion.

As is well known, Bocheński was the first to write a whole book in which he describes in a detailed way the idea of a logic of religion. ${ }^{1}$ This book contains a lot of interesting observations of how a formalization or axiomatization could be done. In this sense, Bocheński has worked out several important preconditions for an axiomatization. They are distributed among the three main topics of the book: (1) Investigating the structure of religious language; (2) Investigating the semantics of religious discourse; (3) Investigating the justification of religious statements.

This paper is divided into the following chapters:

1. Certain facts concerning the structure of religious language established already by Bocheński

2. Difficulties when applying the usual classical logic to religion

3. Problems of the Universe of Discourse

4. How to use definitions?

\footnotetext{
1 Cf. (Bocheński 1965).
}

Paul Weingartner

paul.weingartner@sbg.ac.at

$1 \quad$ Salzburg University, Franziskanergasse 1, 5020 Salzburg, Austria 
5. Analogous concepts and operations

6. The justification of religious statements

\section{Facts established in Bocheński's logic of religion}

Fact 1: Religious believers use a certain language called by Bocheński: Religious Discourse (RD).

Fact 2: In order to apply logic to $\mathrm{RD}$, at least a part of $\mathrm{RD}$ has to be propositional, i.e., the statements in this part are true or false and are called propositions.

Fact 3: It can easily be proved that a part of the RD of the Judaic-Christian Religion is propositional: this RD contains profane statements which are historical or geographical and genuine religious statements which are about God the creator, Christ's incarnation, passion and resurrection etc.

Since a part of religion has to be propositional in order to apply logic to it, the religions referred to in this article are based on a written text. This is most definite in Judaism (Torah or Pentateuch), Christianity (Old and New Testament) and Islam (Koran). It is satisfied in a weaker sense for Buddhism (Sutta Pitaka), Hinduism (Veda) and Confucianism (Lunyü).

\section{Objections to fact 3}

In modern Christian theology it is sometimes claimed that genuine religious statements like the following ones and similar ones have to be interpreted symbolically: "In the beginning God created the heavens and the earth "(Genesis 1,1) or "Jesus took bread and said: Take and eat, it is my body (...) drink from it (...) it is my blood' (...) for the forgiveness of sins" (Mathew 26, 26-28).

And by "symbolically" they mean that the respective sentences are not propositions that are true or false, but expressions that are neither true nor false. The reason for such a claim may be twofold: (1) to save or defend religion from attacks of nonbelievers, (2) error. As to the first, such a "defense" has the opposite effect since the claim will be unmasked as swindle or dishonest excuse. God is the creator of the world or he is not; and a religious believer believes that he is, i.e. that this is true. Similarly, for the other passages. Of course, critical exegesis is included, but also critical exegesis cannot turn such propositions into non-committal sentences without truth-value. As to the second, the claim cannot be correct since it leads to absurd consequences. Some are as follows:

(a) Religious believer and disbeliever lose its meaning and cannot be distinguished anymore. There cannot be belief or disbelief in something that is neither true nor false.

(b) There is no demarcation possible for being or not-being a member of a certain religion if there is no Creed consisting of propositions. 
(c) If the claim would be correct for genuine religious statements in the Bible, then logic is not applicable to genuine religious texts. But the latter can be refuted by showing that important passages of the Bible have a formal valid logical structure. Two examples are as follows. The first one is a true conditional where antecedent and consequent are both false. The second one is a derivation by contraposition.

(i) Thomas Aquinas comments this as follows: "But could Christ say these things ["I do not know him" and "I would be a liar"]? He could indeed have spoken the words materially, but not so as to intend expressing a falsehood, because this could be done only by Christ's will inclining to falsehood, which was impossible, just as it was impossible for him to sin. However, the conditional statement is true, although both antecedent and consequent are impossible."2

(ii) "Then he [Jesus] turned toward the woman and said to Simon: 'Do you see this woman? I came into your house. You did not give me any water for my feet, but she wet my feet with tears and wiped them with her hair (...) Therefore, I tell you, her many sins have been forgiven because of her great love. But whoever has been forgiven little, loves little."' (Luke 7, 44, 47)

The logical inference by contraposition is this:

Great love $\Rightarrow$ many sins forgiven.

Therefore: not many (little) sins forgiven $\Rightarrow$ not great (little) love.

\section{Fact 4: RD contains norms}

At the conference "La Nature de la Verite Scientifique" of the Academie Internationale de Philosophie des Sciences (April 27-29, 1981) in Brussels I told Bocheński that an essential part of RD consists of norms, i.e. of prescriptive statements in addition to propositions. An important example are the Ten Commandments (Exodus 20,3-17; Deuteronomy 5,7-21). Bocheński agreed that this is an essential part of $\mathrm{RD}$ although he did not consider it in his The Logic of Religion.

Norms can be translated into propositions by using that-clauses or some deontic operator: That you shall not steal is true. Lying is forbidden. To honour your father and your mother is obligatory.

The decisive point for our considerations here is that logic and moreover axiomatic thinking can be applied to such norms of God's Commandments as systems of deontic logic show. However, there is the following difference. Deontic Logic is applied logic and is concerned with the logical relations between norms. Examples for principles of deontic logic are: If it is obligatory that $p(O p)$ then it is not forbidden that $p(\neg F p)$. If it is obligatory that if $p$ then $q(O(p \rightarrow q))$ then if it is obligatory that $p(O p)$ then it is also obligatory that $q(O q): O(p \rightarrow q) \rightarrow(O p \rightarrow O q)$. These

\footnotetext{
${ }^{2}$ Cf. CGJ Section 1285.
} 
principles are formal in the sense that no specific content is mentioned, i.e. it is not said what is obligatory or what is forbidden.

God's Commands, however, are contentful informative norms, rules or advices which say what is obligatory or what is forbidden. Examples for such norms are: "Honour your father and your mother, so that you may live long in the land the Lord your God is giving you"; "Love your neighbour as yourself" (Leviticus 19,18; Matthew 22,39; Mark 12,31; Luke 10,27; Galatians 5,14). "Carry each other's burdens", (and in this way you will fulfil the laws of Christ) (Galatians 6,2).

There is however, a most general principle of Natural Law underlying all commands and commandments. It connects values with norms and is also formal: "The good should be done, the bad should be avoided." "3 This principle is value-scale invariant and invariant w.r.t. legal orders, i.e. it holds in all legal orders and is independent of different hiecharchies of values.

\section{Difficulties when applying classical logic (CL)}

Some of the difficulties are very general and not specific concerning the application to religion; some others are specific. We shall deal with some general ones in this section and with some specific ones in Sects. 3 and 4. In Sect. 2 we use only the classical two-valued propositional calculus (CPC).

\section{Principles of CPC which cause difficulties}

One example of such a principle is the principle of addition: $p \Rightarrow(p \vee q)$. It looks as a harmless weakening but it is the culprit of the following paradoxes when CL is applied to empirical science and ethics: Hesse's confirmation paradox, Goodman's paradox, Ross paradox. ${ }^{4}$ Another example is $p \Rightarrow(q \rightarrow p)$. Take $p=$ First Order Predicate Logic is complete and $q=$ Syllogistics is decidable. Then from First Order Predicate Logic is complete it follows that both are logically dependent, i.e. if the second is true, so is the first. Take $p=$ God is allgood, and $q=$ God is not created. Then from God is allgood it follows that if God is not created then he is allgood. A further important example which leads to difficulties is that by CL from every conjunction an equivalence and the respective implications follow logically: $(p \wedge q)$ $\Rightarrow(q \leftrightarrow p) ;(p \wedge q) \Rightarrow(q \rightarrow p)$. Moreover, CL allows that from any two true propositions $\mathrm{p}, \mathrm{q}$ the true conjunction $p \wedge q$ can be built.

From such considerations it is plain that this understanding of derivation and proof is not in accordance with its understanding in mathematics and in science. No mathematician or scientist would dream to derive from two true theorems or from two true results (or their respective conjunctions) that they imply each other, or that one is derivable from the other. Because the two true theorems or the two true

\footnotetext{
3 Cf. Thomas (1948), I-II, 94, 2.

${ }^{4}$ For details and proofs see Weingartner (2001).
} 
results are usually not logically dependent of each other. Take FT to be Fermat's Last Theorem (proved by Wiles in 1995) and PT to be the Poincaré Conjecture (proved by Perelman in 2002) then it would be crazy to claim that $F T \rightarrow P T$, because both are true and can be put into a true conjunction.

Assume that an axiom says that: God is omniscient and God is omnipotent and God is allgood and God is creator of the universe. Then from this true conjunction it follows by CPC that all the four parts (conjuncts) imply each other. This is completely untenable for an attempt to axiomatize religion.

\section{Solution for the difficulties}

To avoid this difficulty for axiomatizing religion in ASG (Weingartner 2021a), the derivations of CL (CPC) are restricted by Intuitionistic Logic and by the relevance restriction $\mathrm{RC}$ (replacement criterion).

$\mathrm{RC}$ forbids valid inferences of CPC in which parts of the consequence class can be replaced by any arbitrary parts (including by their negations) salva validitate of the inference. Such parts cannot be relevant consequences even if they are the result of a CPC-valid derivation. $\mathrm{RC}$ is defined as follows:

$\mathrm{RC} \alpha$ is a relevant (non-redundant) consequence of $\mathrm{A}$ if $\mathrm{A} F \alpha$ or $\mathrm{A} \Rightarrow \alpha$ (according to CPC) and it is not the case that a propositional variable is replaceable in $\alpha$ on some of its occurences by any other propositional variable salva validitate of $A+\alpha$ or $\mathrm{A} \Rightarrow \alpha .^{5}$

Examples: The following principles are CPC-valid but do not satisfy RC (i.e., have irrelevant consequences $): p \Rightarrow(p \vee q) ; p \Rightarrow(q \rightarrow p) ;(p \wedge q) \Rightarrow(q \rightarrow p) ;(p \wedge r)$ $\Rightarrow((p \wedge q) \vee(r \wedge \neg q))$.

In the first two, q can be replaced by any arbitrary propositional variable (including its own negation) salva valididate (of CPC); in the third, the second occurrence of $\mathrm{q}$ and in the fourth both occurrences of $\mathrm{q}$ can be replaced by any arbitrary propositional variable (including its own negation) salva validitate of CPC. ${ }^{6}$

The third example shows that RC forbids to derive an implication (or equivalence) from a conjunction. Such a derivation is also ruled out by Intuitionistic Logic which is also satisfied in ASG (with only few exceptions). This understanding of derivation and proof is in accordance with its understanding in mathematics and in science.

An axiomatization of religion obeying these logical restrictions has been realized in ASG in the following sense: A considerable part of Natural (or Philosophical) Christian Theology (chs. 1-5) and even a part of Christian Theology (ch. 6) has been described by axioms, definitions and derived theorems. It concerns God's essence, omniscience, omnipotence, benevolence, creation (including evil in the world) and

\footnotetext{
5 This criterion originates in Schurz and Weingartner (1987), where it serves to rehabilitate Popper's theory of verisimilitude. Cf. Weingartner (2000b), Weingartner (2009), and Schurz and Weingartner (2010) for further development.

${ }^{6}$ The fourth example plays a role in modern physics since it is one form of Bell's inequalities. Cf. Weingartner $(2009, \S 4)$.
} 
Incarnation. Ch. 7 contains a consistency proof of a considerable part of ASG with the help of a model which is a 10-valued decidable logic. A part of this axiomatization is also used in THEO (Weingartner 2021c).

\section{Problems of the universe of discourse (UD)}

The assumption of First Order Predicate Logic as a part of CL that its UD is nonempty is very well justified if the individual variables run over things of the universe or creatures. Since we know that human beings, living things and non-living things of our universe exist in space and time, the UD for the variables referring to creatures cannot be empty. However, this assumption is too strong if the individual variables run over persons like God or angels. The reason is that in the non-empty UD of CL the proposition $(\exists x)(x=\mathrm{a})$ is a truth of logic. From this it follows that $(\exists x)$ $(x=g)$ (' $\mathrm{g}$ ' for God), i.e. that God exists. Thus, God's existence would be a matter of Classical Logic and this is of course untenable. Therefore, such existence assumptions have to be explicitly made by special axioms as it is done in ch. 1 of ASG.

In consequence of that the UD for creatures cannot be the same as the UD for supernatural beings. Whereas the first must be non-empty the second must be allowed to be empty. This means that the logic to be applied to religion has to be at least two-sorted. If trinity is included, as in Christian Religion, we have to assume a third UD; since the individual variables referring to the three divine persons have to be different from those, or from the respective individual constant, referring to the triune God. Therefore, in this case, the underlying logic has to be three-sorted as in ASG. It also holds of the third UD that it is allowed to be empty. In other words, the existence of the three divine persons have to explicitly stated by an axiom (axiom A2 in ASG).

Many articles concerning proofs of the existence of God with the help of formal logic use only one UD. This means that these articles or their respective authors do not care to put God together with contingent individuals (his creatures) into one UD. ${ }^{7}$ Because of the enormous difference between an infinite, necessary, omniscient, omnipotent (...) etc. being and finite, contingent, fallible, limited (...) etc. beings such an equalization is completely unacceptable. What has to be done at least is to restrict variables to creatures or contingent things with the help of restricted quantifiers: $\forall x \in \mathrm{W}, \exists x \in \mathrm{W}$ (for all, some $\mathrm{x}$ belonging to the world). Certainly this means that in cosmological arguments the "bridge" between the world or things of the world and God has to be explicitly stated in at least one of the premises.

In the discussion to my talk Jan Woleński gave the advice to use "God" as a predicate in order to avoid that his existence follows from the logic of identity. This, however, is only a preliminary and not a real solution to the problem. It seems first a solution on the lowest type-level, but the problem comes back with the question to which entity this predicate belongs. Does this entity belong to the individuals of the single UD or who is the bearer of this predicate? On the first type level the question

\footnotetext{
7 Several examples of this kind can be found in Szatkowski (2012).
} 
is whether this predicate " $\mathrm{G}$ " is just one among the other predicates attributed to the contingent things etc. Because of such difficulties a two-sorted logic with two different universes of discourse seems to be more suitable.

\section{How to use definitions?}

\section{Two views of definitions}

There are two main-views concerning definitions in the more recent tradition of logic. The one is due to Russell, described in a short and concentrated way on page 11 of Principia Mathematica (2nd ed. 1927):

"Definitions are (...) strictly speaking, mere typographical conveniences." "For a definition is concerned wholly with the symbols, not with what at they symbolize. Moreover, it is not true or false." Moreover, the sign "=Df" is not any functor of Principia Mathematica, but a sign in the metalanguage combining two expressions on the level of the object language. ${ }^{8}$

The other view is that of the Lvov-Warsaw School. In this case definitions are true equivalences and the sign " $\Leftrightarrow$ " is a functor of the object language of the system. Its main points - the criteria of eliminability and non-creativity-are due to Lesniewski and Tarski. ${ }^{9}$ Already according to Aristotle definitions are true equivalences. And if the essence concerning a species is defined then the equivalence is necessary. Moreover, Aristotle had a restricted criterion of non-creativity: From a definition no existential statement can be derived; most importantly it cannot be derived that the referent of the definiendum or that of the definiens or that of a part of definiens exists. ${ }^{10}$

The important definitions in mathematics and in science satisfy the view of the Lvov-Warsaw School, they are true or false. This can be proved by the fact that the question of their truth or validity is investigated and that they can be revised and improved by new knowledge. As Kreisel puts it, "the motto 'Definitions are just stipulations and therefore neither true (valid) nor false, but a matter of expediency' is grotesque: since for more than 2000 years some central questions of the form 'What is (object) $\mathrm{X}$ ' are answered by-of course valid-definitions". ${ }^{11}$

\section{Definitions in axiomatizations of religion}

It is plain that such definitions have to be viewed according to the Lvov-Warsaw School as true (or approximately true) equivalences. Even if it is a problem to propose a definition of God at all, it would be ridiculous to call such a definition a

\footnotetext{
${ }^{8}$ Cf. Weingartner (1989) and (2000a, ch. 5). Merely abbreviations which are sometimes called definitions like 'U.L.' for 'university library' or DNA do not create problems and do not need a theory of definitions at all.

9 Cf. Tarski (1956, ch. X) and Suppes (1957, ch. 8).

${ }^{10}$ Cf. Weingartner (1991).

11 See (Kreisel et al. 1981, p. 186).
} 
typographical convenience. This also holds in less problematic cases where it is defined what is meant by saying that God has certain attributes, for example that God is perfect or that God is eternal.

In such cases a certain peculiarity comes up. Usually, the definiendum contains a variable that can be universally quantified. Thus, we could try to define $x$ is perfect or $x$ is eternal. Then the universe of discourse of these variables would include either God and creatures or only God. Because of the essential difference(s) between God and creatures it cannot be accepted to put them both into one universe of discourse. Moreover, it would not be a way out to have two separate universes (UD) and to use superposing variables for the universe of both. Therefore, it can only be accepted that the respective UD only contains God as a reference since it is clear from the very beginning that only God can be perfect and eternal. But then it makes no sense to use variables. In consequence of that such definitions using constant ' $\mathrm{g}$ ' (God), in the definiendum can be viewed like an instance of a virtual universal definition which in this case does not exist. The situation is similar when we make an instance of the definition of man:

Definition of man: $x \in$ Man $\Leftrightarrow x \in$ Animal $\wedge x \in$ Rational

Definition of: Socrates is a man: $s \in \operatorname{Man} \Leftrightarrow s \in$ Animal $\wedge s \in$ Rational

This is a particular instance of the above definition of man where ' $s$ ' is a constant standing for Socrates. There is an important point to notice here: the first is a definition of a general concept man and therefore we must have a variable in the definiendum. The second definition which is an instance of the first is not a definition of man but of Socrates is a man. Analogously we do not define perfection and eternity, but God is perfect and God is eternal. This also holds for the definitions of the other properties of God like being logically omniscient, logically infallible, or for saying what it means that God permits or causes some states of affairs.

\section{Analogous operations}

\section{Operations}

It is evident that knowledge, will and causation must have an analogous meaning, but cannot have the same meaning in the following two groups of propositions: $x$ knows that $p, x$ wills that $p, x$ causes that $p$ (where ' $x$ ' refers to human beings) and $g$ knows that $p, g$ wills that $p, g$ causes that $p$ (where ' $g$ ' refers to God).

The strength of the analogy relation depends on stronger or weaker similarity. Thus if we assume a strong concept of knowledge for human beings then the similarity between $x$ knows and $g$ knows is greater than that between $x$ wills and $g$ wills. The reason is that it holds: If God knows that $p$ then $p$ is true and if $x$ knows that $p$ then $p$ is true. For God this also holds for his will and causation: Whatever God wills obtains and whatever God causes is the case. This does not hold for humans. Observe that statements as "God wills that men obey his commandments" (which is not always the case) are no objections, since they are ill formulated. In respect to 
free will actions of men the correct formulation is: God wills that men should obey his commandments, since God does not destroy men's free will.

A further difference is that God can direct his will to both to himself and to his creation, but he can direct his causation only to his creation: God can will his own goodness but he cannot cause it. For humans it holds that they can direct both will and causation to themselves and to things different from them. Thus they can will and cause the improvement in their skills and in their virtues.

Despite a great literature about analogy, there are only few studies which could be helpful for an axiomatization of religion. One is the seminal article "On Analogy" by Bocheński which has some preparatory work in Salamucha and Drewnowski as Bocheński says there in a note. In a further development the concept of analogy is extended from a relation between two names to a relation among things in general (including linguistic things). ${ }^{12} \mathrm{I}$ do not know of some work in which analogy relations among operations or actions are investigated with precise logical means. This seems to be still a wide and interesting field of research which can serve for axiomatizing religion.

\section{Epistemic principles}

At the end of this section I shall pick out one question concerning epistemic principles which are concerned with the analogy of the operations contained in them: The following two distribution principles for the operation knows are understood as basic and valid in Epistemic Logic:

$(\forall p, q)(\forall x \in \mathrm{H})[x K(p \wedge q) \rightarrow(x K p \wedge x K q)]$

$(\forall p, q)(\forall x \in \mathrm{H})[x K(p \rightarrow q) \rightarrow(\mathrm{x} K p \rightarrow x K q)]$

Can we assume that these two principles also hold for God? The reason to ask this question is that in an axiomatization of God's knowledge and omniscience such principles could be used as axioms. In ASG the second principle (distribution of $\mathrm{K}$ over $\rightarrow$ ) is used to prove that God is logically infallible. This could be proved in another way too, since it is a theorem there that God knows all logical truths. However, such considerations lead to an important point: Every axiomatization of religion is an axiomatization of our understanding of God and of religious statements concerned in a more direct or indirect way with God. This does not mean that such an approach is only subjective, since it may be supported by the revealed text of the Bible. However, any such axiomatization, even if best supported by biblical and Church Documents is not an axiomatization of God's thoughts, since:

"For my thoughts are not your thoughts neither are your ways my ways" (Isaiah $55,8)$.

12 Bochenski (1948), Cf. Weingartner (1976, ch. 6.4; 1979; 1998/1999). 
Nevertheless, investigations whether God's thoughts as revealed in the Bible (according to critical exegesis) obey the law of non-contradiction are valuable ${ }^{13}$ since they help us to have a consistent interpretation and understanding of the texts and of God. Moreover, they help to refute wrong attacks and logical fallacies brought forward against religion.

\section{The justification of religious statements}

In chapter $\mathrm{V}$ of his The Logic of Religion Bocheński discusses the justification of religious discourse. Besides of other strategies he describes a very important kind of justification of religious statements by epistemic authority. Both concepts, that of epistemic authority and that of deontic authority are inventions of Bocheński himself and have been defined and described by him. ${ }^{14}$ I shall discuss the problem of the justification of religious statements from another point of view: From the credibility of belief systems; more specifically from a comparison of the credibility between scientific belief systems (SBS) and religious belief systems (RBS).

Observe that it is justified to talk of scientific belief-systems: Most of what scientists "know" they believe their colleagues. What they genuinely know is relatively small in proportion to that what they believe. Of course, they believe their colleagues in a rationally justified way, since they trust their results which are based on an accepted scientific methodology. Subsequently I shall formulate two criteria and two norms for the credibility (CRD) of a belief system (BS) which are applicable to the CRD of religion. ${ }^{15}$

\section{Criterion 1 for the credibility of religion}

\section{Upper bound for the credibility of a belief-system}

Thesis 1: For every particular belief system concerning some domain, there is an upper bound for the credibility of it. This upper bound is a threshold beyond which a rational justification of that belief system is impossible.

Example: Assume the belief system to be Physics. Then the requirement that the degree of credibility is verfication is beyond the upper bound. As is well-known, verification of universal physical laws is impossible. We cannot investigate all metals in the universe in order to verify: all metals, when heated, expand. We cannot verify $E=m c^{2}$; not only because most of the masses of the universe are not accessible to us but also because of the technical difficulties to convert mass into energy. On the other hand corroboration by testing consequences of the laws is below the upper bound and is therefore a candidate for credibility.

\footnotetext{
${ }^{13}$ Cf. Heller (2019) and ASG Section 1.5.1.

14 Bocheński (1965 Appendix 51.1) and Bocheński (1988 ch.1).

15 A detailed study "On the Credibility of Religion" will appear in the journal Theologie und Philosophie 2021 (Weingartner 2021b).
} 


\section{Requirement for religious belief systems}

Norm 1: It should not be required that the degree $d r$ of credibility (CRD) for a particular religious belief system (RBS) must be higher than the degree $d s$ of CRD for any scientific belief system (SBS).

Since it cannot be required that the degree $d s$ of SBS is higher than its upper bound (which would make a rational justification of SBS impossible) this cannot be required either of the degree $d r$ of CRD for any RBS.

\section{Internal consistency}

\section{Is it rationally justifiable to require internal consistency for the CRD of a BS?}

The answer to this question depends very much on whether the whole of a huge $\mathrm{BS}$ is concerned or only certain parts of it. We consider first the whole of certain BS.

(1) Take SBS to be the whole of mathematics; or take ZF-Set Theory of NBG-Set Theory from which a great part of whole mathematics can be deduced. Then to require a proof of internal consistency for the CRD of SBS is beyond the upper bound; this follows from Gödel's second incompleteness theorem.

(2) Take SBS to be the whole of physics. Then to require internal consistency of the CRD of SBS goes beyond the upper bound (we may say, at least so far). In $\mathrm{CM}$ (Classical Mechanics) an object has a continuous trajectory and has identity over time. In QM (Quantum Mechanics) a QM-object does not have a continuous trajectory and is (as an individual object) not identifiable over time; Identity over time holds only for the kind of objects (electrons, neutrons, photons, protons,... etc.) because of permutation invariance. There are further well-known incompatibilities.

(3) Take RBS to be the whole Christian Revelation documented in the canonical scriptures. This is defined by the Synode of Rome (382) and the councils of Florence (1442) and Trent (1546). Cf. Denzinger (2005) D179, 180, 1335, 1502, 1503. These are scriptures of the Old and New Testament.

Should we require a proof for the internal consistency of the whole Christian Revelation documented in the canonical scriptures of the Old and New Testament? It follows from (1) and (2) above together with Norm 1 that this should not be required. Since the requirement for showing the internal consistency of the most strongest scientific domains, mathematics and physics, goes beyond the upper bound of credibility it should not be required for a religious BS either. 


\section{Is it rationally justifiable to require internal consistency for the CRD of an essential part of a huge BS?}

We think that such a requirement is rationally justifiable and does not go beyond the upper bound for CRD of a huge BS. This can be substantiated as follows: Gentzen proved the consistency of First Order Peano Arithmetic; the theory of real closed fields is consistent and decidable. Classical Mechanics (CM) is apparently internal consistent, although some hidden assumptions like universal time and simultaneity are external inconsistent with SR (Special Theory of Relativity). SR seems to be internal and external consistent.

The internal consistency for the CRD of an essential part, seems also to be rationally justified for a religious belief system (RBS). An example for an essential part of a RBS is the "Creed". As Bocheński $(1965,3.4)$ says the Creed of a religion is of such an importance that a person can be called a member of a certain religion if $\mathrm{s} / \mathrm{he}$ believes all the statements of the respective Creed. As is clear from 1.2 we have to add the belief in the validity of norms for example the Ten Commandements. Since the Creed is of such an importance for a religion - this holds especially for Judaism, Christianity and Islam, because their Creed is based on written texts - it is rationally justified to require internal consistency of the respective Creed. This is the more the case because it holds for the respective religion or RBS that the Creed should be believed (or is obligatory to be believed) by every member of the respective religion.

\section{Criterion 2 for the credibility of religion}

\section{Lower bound for the credibility of a belief-system}

Thesis 2: For every particular BS concerning some domain there is a lower bound for the credibility of it. This lower bound is a threshold below which a rational justification of that $\mathrm{BS}$ is impossible or hardly possible.

Examples:

(1) Take the BS to be the cosmological theory of the Big Bang. This theory has three strong supports: The expansion of the universe, the singularity theorems of Hawking and Penrose and the discovery of the cosmic background radiation by Penzias and Wilson. Assume now that none of these supports were true or available: The universe would be static and not expanding (Einstein's original conjecture), no singularity theorem could be proved and the cosmic background radiation has not been discovered or did not exist. Then the credibility of the Big Bang theory would be below its lower bound; a rational justification would hardly be possible.

(2) Take the BS to be the Torah (the first five books of the Old Testament). The second book of the Torah the book "Exodus" describes the exodus of the people of Israel from Egypt (see Ex 12,17;31. 13,8;14.23,15). It happened during the government of Ramses II (1304-1237). This description has further support in other books of the Bible. First in book Leviticus $(23,43)$ and Deuteronomy 
$(6,20-23 ; 16,1 ; 26,5-10)$ which both belong to the Torah. Second in the Psalms (Ps 78; 12,43,51), in Joshua $(4,23)$ and in Judges $(8,23)$ all belonging to the Old Testament. Third there are supports in the New Testament, for example Acts 7,$6 ; 36$. Heb 3,16; 8,9, Jude 5. It is presupposed that these supports are the result of critical exegesis. Suppose now that except the description of the exodus in the book "Exodus" there is no mentioning of this important historical fact in any other part of the Bible (Old and New Testament). Then the credibility of the exodus would be on the boarder of the lower bound or below it. A rational justification for such a disconnectedness to other parts of the Bible would hardly be possible.

(3) Similar justifications or reasons for the credibility being higher than the lower bound can be given for Christ's incarnation, for his passion and for his resurrection.

\section{Requirement for religious belief systems}

Norm 2: If it is required that the degree $d s$ of CRD for any SBS is higher than or equal to the lower bound $d(d s \geq d)$ then it should also be required that the degree $d r$ of CRD for any RBS is higher than or equal to $d(d r \geq d)$.

Since it cannot be permitted that the degree $d s$ of SBS is lower than its lower bound (which would make a rational justification of SBS impossible) this cannot be permitted either of the degree $d r$ of CRD for any RBS. Therefore: If the permission that the degree $d s$ of CRD of any SBS is lower than $d(d s<d)$ leads to the impossibility of a rational justification of SBS then it is not permitted that the degree $d r$ of CRD for any RBS is lower than $d(d r<d)$.

\section{The question of circularity}

\section{There is some difficulty from which all RBS seem to suffer}

One important reason in order to keep the degree of CRD for RBS above the lower bound is that the text is revealed by God. However that this text is revealed by God is said only by this very text itself and is not guaranteed by some source outside. Thus there is no ultimate external resource that can provide an absolute justification for the RBS as based on a text as revealed. When it is said that Moses or the apostles have been witnesses and made proof by observation (hearing the voice of God or seeing and hearing Christ) then the problem is that we know this only from that very text which should be made credible by Moses or by the Apostles. It seems that this kind of circularity cannot be escaped.

\section{It is an interesting fact, however, that this kind of circularity has a striking analogy in science}

An example is the experimental tests for corroborating or confirming the Special Theory of Relativity (SR). The underlying methodological assumptions are these: 
(i) Physical measurement instruments (rods and clocks) are real physical objects, not ideal entities. (ii) Because of (i) they have to obey physical laws. But which ones? According to the Copenhagen-Interpretation, quantum-mechanical phenomena have to be measured by a measurement instrument "outside" the QM-System which obeys the laws of Classical Mechanics. Einstein refused this view for both, his Theory of Relativity and for Quantum Mechanics. Therefore, he required (iii). (iii) The measurement instruments (rods and clocks) applied to test the Special Theory of Relativity (SR) have to obey the laws of SR:

It is plain that assumption (iii) leads to a kind of circularity: The measurement instruments which are used to test SR presuppose and obey the laws of SR since they are real physical objects and not ideal independent measures.

Does this mean that such a test is not reliable? As the facts show, this is not the case and moreover reveals that this is the only way to test predictions of SR, i.e., time-dilatation (tested by Hafele and Keating ${ }^{16}$ ) and mass-increase (tested by particle accelerators).

\section{The situation in both cases of circularity is this}

The test for the confirmation of SR or RBS is made either by instruments ruled by $\mathrm{SR}$ or by events described in RBS, in neither case independent of SR or RBS. In general, such a situation reveals a fact which we have learned from the Theory of Relativity: We cannot have an ultimate external measurement apparatus outside and separated from the physical system to be measured by it.

Similarly, there is no external absolute last resort, available to us now, and independent of RBS, which could be used to confirm RBS. Every test of SBS or of RBS is relative in this sense without being unreliable.

Funding Open access funding provided by Paris Lodron University of Salzburg.

Conflict of interest The author declares that there is no conflict of interests.

Open Access This article is licensed under a Creative Commons Attribution 4.0 International License, which permits use, sharing, adaptation, distribution and reproduction in any medium or format, as long as you give appropriate credit to the original author(s) and the source, provide a link to the Creative Commons licence, and indicate if changes were made. The images or other third party material in this article are included in the article's Creative Commons licence, unless indicated otherwise in a credit line to the material. If material is not included in the article's Creative Commons licence and your intended use is not permitted by statutory regulation or exceeds the permitted use, you will need to obtain permission directly from the copyright holder. To view a copy of this licence, visit http://creativecommons.org/licen ses/by/4.0/.

${ }^{16}$ Hafele and Keating (1972). 


\section{References}

Bocheński, J. M. (1948). On analogy. The Thomist, 11, 474-497.

Bocheński, J. M. (1965). The logic of religion. New York: New York University Press.

Bocheński, J. M. (1988). Autorität, Freiheit, Glaube. Sozialphilosophische Studien. München: Philosophia Verlag.

Denzinger, H. (2005). Enchiridion symbolorum definitionum et declarationum de rebus fidei et morum. Kompedium der Glaubensbekenntnisse und kirchlichen Lehrentscheidungen. Ed. P.Hünermann. 40th. Edition, Freiburg: Herder.

Hafele, J. C., \& Keating, R. E. (1972). Around the world atomic clocks. Science, 177, 166-170.

Heller, M. (2019). The logic of god. Edukacja Filozoficzna, 68, 227-244.

Kreisel, G., et al. (1981). Zur Bewertung mathematischer Definitionen. In E. Morscher (Ed.), Philosophie als Wissenschaft/Essays in scientific philosophy (pp. 185-207). Bad Reichenhall: Comes Verlag.

Schurz, G., \& Weingartner, P. (1987). Verisimilitude defined by relevant consequence-elements. A new reconstruction of Popper's original idea. In T. Kuipers (Ed.), What is closer-to-the-truth: A parade of approaches to truthlikeness (pp. 47-77). Amsterdam: Rodopi.

Schurz, G., and Weingartner, P. (2010). Zwart and Franssen's impossibility theorem holds for possibleworld-accounts to verisimilitude. Synthese, 172(3), 415-436.

Suppes, P. (1957). Introduction to logic. Princeton: Princeton University Press.

Szatkowski, M. (2012). Ontological proofs today. Frankfurt a. M.: Ontos.

Tarski, A. (1956). Logic, semantics. Oxford: Oxford University Press.

Thomas, A. (1948). Summa Theologica vol. 5. Transl. by Fathers of the English Dominican Province. Christian Classics. Maryland: Westminster. Reprinted: 1981. Abbreviated as STh.

Thomas, A. (2010). Commentary on the Gospel of St. John. Part II. Ed. J.A. Weisheipl and F. Larcher. Petersham, Mass.: St. Bede's Publications. Abbreviated as CGJ.

Weingartner, P. (1976). Wissenschaftstheorie II, 1. Grundlagenprobleme der Logik und Mathematik. Stuttgart: Frommann-Holzboog.

Weingartner, P. (1979). Analogy among systems. Dialectica, 33, 355-378.

Weingartner, P. (1989). Definitions in Russell, in the Vienna-Circle and in the Lvov-Warsaw School. In K. Szaniawski (Ed.), The Vienna Circle and the Lvov-Warsaw School (pp. 225-247). Dordrecht: Kluwer.

Weingartner, P. (1991). A note on Aristotle's theory of definition and scientific explanation. In W. Spohn (Ed.), Existence and Explanation (pp. 207-217). Dordrecht: Kluwer.

Weingartner, P. (1998/99) Bocheński: Attempts to apply logic to problems of religion. Philosophia Scientia, 3(4), 175-198.

Weingartner, P., et al. (2000). Reasons for filtering classical logic. In D. Batens (Ed.), Frontiers of paraconsistent logic (pp. 315-327). Baldock: Research Studies Press.

Weingartner, P. (2000a). Basic questions of truth. Dordrecht: Kluwer.

Weingartner, P. (2001). Applications of logic outside logic and mathematics: Do such applications force us to deviate from classical logic? In W. Stelzner (Ed.), Zwischen traditioneller und moderner Logik (pp. 53-64). Paderborn: Mentis.

Weingartner, P. (2009). Matrix based logic for application in physics. The Review of Symbolic Logic, 2, $132-163$.

Weingartner, P. (2021a). An axiomatic study of god. A defence of the rationality of religion. Berlin, De Gruyter. Abbreviated as ASG.

Weingartner, P. (2021b). On the credibility of religion. Theologie und Philosophie.

Weingartner, P. (2021c). Theodicy_From a logical point of view. Berlin: Peter Lang. Abbreviated as THEO.

Publisher's Note Springer Nature remains neutral with regard to jurisdictional claims in published maps and institutional affiliations. 